\title{
THE NON-CLASSICAL ERROR THEORY OF MEASUMERMENTS (THE NETM)- AS A NEW EFFECTIVE METHOD OF MATHEMATICAL PROCESSING OF MODERN SCIENTIFIC EXPERIMENTS
}

НЕКЛАСИЧНА ТЕОРІЯ ПОХИБОК ВИМІРІВ (НТПВ) - ЯК НОВИЙ ЕФЕКТИВНИЙ ЗАСІБ МАТЕМАТИЧНОЇ ОБРОБКИ СУЧАСНИХ НАУКОВИХ ЕКСПЕРИМЕНТІВ

\begin{abstract}
The classical error theory (CET) and the least square method (LSM) that flow from it, which remain one of the main tools of mathematical modeling, was created in 1823 by the prominent German mathematician, C. F. Gauss. The CET has become widely used in mathematical processing of the results of scientific and technical measurements for the last 150 years. But their number has increased immeasurably with the beginning of the space era and the automation of measurements. However, there was their very interesting feature - discrepancy of the fundamental concept of the CET, which is mainly non-Gaussian character of multiple measurements, which have a volume $n>500$. The NETM in the first approximation is based on the CET methods but has a completely different axiomatic basis and is used for mathematical processing of modern, automated scientific and technical experiments with a large volume of measurements. I
\end{abstract}


The purpose of the research: to acquaint experimental scientists with the NETM axioms, features and areas of its use, the results of checking the adequacy of its postulates at the Main Astronomical Observatory of the Academy of Sciences of Ukraine.

Methods: probability and mathematical-statistical procedures are used in the NETM, which ensure the effectiveness of estimations of the studied parameters and diagnostics of mathematical modeling.

The results of the research: the justified necessity of applying the new error law with the volumes of samples $n>500$, in accordance with the recommendations of professor of the University of Cambridge H. Jeffreys.

Scientific novelty: a general description of the NETM procedures is given for the first time for the purpose of obtaining effective evaluations of the desired parameters of statistical distributions based on the use of the Pearson-Jeffreys error law with observation volumes $n>500$.

Practical significance: the study is to uncover the universal nature of the NETM methods in processing multiple observations of large volumes in various fields of science and technology.

Conclusion: the Non-clasical Error Theory, which was created at the Faculty of Cybernetics of the Academician Stepan Demianchuk International University of Economics and Humanitiesr in 2015, has passed many years of testing and proved its effectiveness in the mathematical processing of modern scientific and technical measuring experiments of a large volume. The use of the NETM in the analysis of data allows solving three important problems, namely:

1) Use modern, adequate representation of the error distribution law of observations of large volumes.

2) Obtain effective estimates of the fundamental distribution of the NETM - the Pearson-Jeffreys law and its most important characteristic - the parameter $m$, which is a measure of the deviation of the statistical distribution from the Gauss law and is the main metrological characteristic of the observation method.

3) Solve the problem of weighing abnormal errors.

\section{Анотація}

Класичну теорію похибок (КТП) і витікаючий з неї метод найменших квадратів (МНК), які до цього часу лишаються одним із основних інструментів математичного моделювання, створив видатний німецький математик К. Ф. Гаус ще в 1823 р. На протязі 150 років КТП набула широкого використання при математичній обробці результатів наукових і технічних вимірів. Але з початком космічної ери і автоматизацією вимірів їх кількість незрівнянно зросла. При цьому виявилась одна дуже цікава особливість багатократних 
вимірів - їх невідповідність фундаментальній концепції КТП, а саме, переважно негаусовий характер вимірів, які мають обсяг $n>500$. НТПВ в першому наближенні, грунтується на методах КТП, але має зовсім іншу аксіоматичну основу і застосовується для математичної обробки сучасних, автоматизованих наукових і технічних експериментів з великим обсягом вимірів.

Мета дослідження: ознайомити науковців-експериментаторів з аксіоматикою НТПВ, особливостями і сферами їі використання, результатами перевірки адекватності ії постулатів в Головній астрономічній обсерваторії Академії наук України.

Методи: в НТПВ задіяні ймовірнісні і математико-статистичні процедури, які забезпечують ефективність оцінок досліджуваних параметрів.

Результати дослідження: обгрунтована необхідність застосування нового закону похибокпри обсягах вибірок $n>500$ у відповідностіз рекомендаціями професора Кембріджського університету Г. Джеффріса.

Наукова новизна: вперше дана загальна характеристика процедур НТПВ 3 метою отримання ефективних оцінок шуканих параметрів статистичних розподілів на основі використання закону похибок Пірсона-Джеффріса при обсягах спостережень $n>500$.

Практична значимість: дослідження полягає в розкритті універсального характеру методів НТПВ при обробці багатократних спостережень великих обсягів в різних галузях науки і техніки.

Висновок: Некласична теорія похибок, яка створена на факультеті кібернетики Міжнародного економіко-гуманітарного університету імені академіка Степана Дем'янчука в 2015 р., пройшла багаторічну апробацію і показала свою ефективність при математичній обробці сучасних наукових і технічних вимірювальних експериментів великого обсягу. Застосування НТПВ при аналізі даних дозволяє вирішити три важливі проблеми, а саме:

1) Використовувати сучасні адекватні уявлення про закон розподілу похибок спостережень великих обсягів.

2) Отримати ефективні оцінки фундаментального розподілу НТПВ - закону Пірсона-Джеффріса і його найважливішу характеристику - параметр $m$, який $\epsilon$ мірою відхилення статистичного розподілу від закону Гауса і $€$ основною метрологічною характеристикою метода спостережень.

3) Вирішити проблему зважування аномальних похибок.

KeYworDs: $n$ non-classical and classical error theory, effective estimation, Pearson-Jeffreys law, Gauss law, data analysis.

Ключовг слова: некласична і класична теорії помилок, ефективне оцінювання, закон Пірсона-Джеффріса, закон Гауса, аналіз даних. 


\section{Вступ}

Основна причина, яка показала, що в наш час КТП є вже недостатнім інструментом математичної обробки сучасних експериментів, проявилась непомітно. На жаль, математики на неї вчасно не зреагували. Цією причиною $є$ різке зростання обсягів наукової і технічної вимірювальної інформації у зв'язку з автоматизацією експериментів. Здавалося б, яке значення має це для математичної обробки даних: адже фундаментальні аксіоми, які закладені в основу КТП математичними геніями, мусять ще сильніше підтверджуватись з ростом інформації. Насправді ж все виявилось навпаки: із зростанням обсягів спостережень все ясніше проявлялась невідповідність фундаментальних аксіом КТП реальній практиці спостережень. Наприклад, фундаментальним положенням КТП є гіпотеза нормальності похибок. Дослідники експериментатори стали помилково думати, що всі похибки спостережень мусять наближатись, із зростанням числа спостережень, до закону Гауса, як до своєї ідеальної граничної форми. I це незважаючи на те, що сам Гаус [Gauss C. F., 1823] зазначив, що ніхто не може сказати, яким насправді буде закон похибок, якщо спостереження продовжувати до нескінченності.

\section{Перші автоматизовані системи спостережень i їх закон похибок}

Одні $з$ перших автоматизованих систем спостережень появились в широтній астрометрії. Такою була автоматизована і плаваюча на ртуті астрономічна труба Куксона [Hattory, 1951], встановлена в Грінвічській обсерваторії (Англія). Тому саме аналіз масових широтних спостережень в Грінвічі дозволив знаменитому кембріджському професору Гарольду Джеффрісузробити висновок про негаусовий характер їх похибок [Jeffreys Н., 1937, 1939, 1940]. Сер Гарольд не тільки зробив впевнений висновок про некласичний характер похибок спостережень широти в Грінвічі, але і запропонував досконалу форму нового закону похибок, адекватного практиці сучасних спостережень. На відміну від закону Гауса, запропонований Джеффрісом новий розподіл похибок мав вже три параметри: математичне сподівання характеристику розсіювання і особливий параметр $m$ - міру відхилення дійсного розподілу похибок від закону Гауса. 
Тобто новий, закон похибок був функціонально пов'язаний із класичним нормальним розподілом. А це означає не революцію в області аналізу даних, - ніякі революції нічого не дають, - а реальну і необхідну еволюцію класичних процедур, еволюцію, яка вкрай необхідна в сучасних умовах.

3 врахуванням вище зазначених позначень параметрів, нова форма щільності імовірності закону похибок, запропонованою Джеффрісом, має вигляд [Jeffreys, 1937]:

$$
f(x)=\frac{\Gamma(m+1)}{\sqrt{2 \pi(m-0,5)} \cdot \Gamma(m+0,5)} \cdot \frac{1}{\sigma}\left[1+\frac{0,5}{M}\left(\frac{x-a}{\sigma}\right)^{2}\right]^{-m},
$$

$M=(m-0,5) 3 \cdot m-2 ;$ де $(m)$ - гама-функція;

$a, \sigma, m-$ параметри розподілу (1).

\section{КРИТИКА ІСНУЮЧИХ ФОРМУЛ НЕГАУСОВИХ РОЗПОДІЛІВ І УНІКАЛЬНІСТЬ ЗАКОНУ ПОХИБОК, ЗАПРОПОНОВАНОГО ДЖЕФФРІСОМ}

Варто сказати, що найрізноманітніші криві негаусових розподілів похибок застосовувались і після Джеффріса [Kemnits, 1971, 1978; Markuze, 1985; Orlov, 1991; Volzhanin, 1984]. Загальним, серйозним і основним недоліком всіх цих застосувань, на який, по незрозумілим причинам, більшість авторів не звернула уваги, була недіагональність інформаційних матриць використаних розподілів. Ці автори вважали, що оцінку параметрів застосовуваних негаусових розподілів можна робити так, як для закону Гауса, не турбуючись про можливу залежність їх параметрів. В той же, час незалежність параметрів розподілу похибок має місце тільки і лише тільки для закону Гауса [Genry, 1936; Lukacs, 1942]. Саме ця обставина і обумовлює найперш виключну простоту і ясність КТП. Унікальна особливість запропонованого Джеффрісом розподілу (1) полягає в тому, що він має, як і закон Гауса, незалежні параметри. Жоден із трипараметричних розподілів такої властивості не має. В цьому якраз і полягає науковий подвиг Г. Джеффріса і разом з тим це є свідченням його найвищого професіоналізму, який взагалі властивий вченим Кембріджського університету. 


\section{КОЛИ ПРОЯВЛЯЄТЬСЯ НЕГАУСІВ ХАРАКТЕР РОЗПОДІЛУ ПОХИБОК}

Проаналізувавши в роботі [Jeffreys Н., 1937] відомий експеримент К. Пірсона [Pearson K., 1902] Джеффріс зробив висновок, що негаусів характер емпіричних розподілів стає помітним при обсягах багатократних спостережень $n>500$, в усякому разі при $n<500$ важко критеріально доказати відмінність дійсного розподілу похибок від закону Гауса. Це означає насправді, що нормальний розподіл не має статусу деякого граничного закону похибок, тієї ідеальної форми, якій обов'язково мають підкорятись похибки при зростанні їх обсягів. Зовсім ні. Закон Гауса має продуктивний характер лише для певного інтервалу на осі обсягів вибірок. Пропонуючи застосувати нову концепцію розподілу похибок спостереженьприматематичній обробціданихвеликогообсягу,Джеффріс у роботах [Jeffreys Н., 1937, 1939, 1940] називає розподіл (1) розподілом Пірсона VII типу. Насправді ж класичний розподіл Пірсона VII типу має недіагональну інформаційну матрицю. Цей розподіл він суттєво змінив і довів його до форми (1), яка має діагональну інформаційну матрицю Фішера. Серу Гарольду була властива велика наукова скромність як великому вченому і високоморальній людині. Тому він не дав особливої назви тому досконалому розподілу, який він сам створив. Для того, щоб уникнути накладення різних понять, що в математиці недопустимо, ми будемо далі форму (1) називати розподілом Пірсона-Джеффріса VII типу, або просто законом Пірсона-Джеффріса. Така назва розподілу (1) дозволяє уникнути плутанини і буде справедливою по відношенню до досягнення Джеффріса, який створив єдиний трипараметричний розподіл з ексцесом $\mathcal{E}>0$, що має незалежні параметри, як і закон Гауса. Це також дозволяє, при застосуванні некласичних процедур аналізу даних і при математичному моделюванні, успішно використовувати в першому наближенні КТП.

\section{ФУНДАМЕНТАЛЬНА ПЕРЕВІРКА ВИСНОВКІВ ДЖЕФФРІСА В АКАДЕМІЇ НАУК УКРАЇНИ}

Означені вище висновки Г. Джеффріса були досить несподіваними для більшості вчених в 70-80-х роках минулого століття. Тому в Академії 
Наук України була розроблена спеціальна програма фундаментальної перевірки викладених вище висновків Джеффріса. Ця програма розроблена під керівництвом директора Головної астрономічної обсерваторії академіка Е. П. Федорова. Для реалізації програми були використані майже усі опубліковані масиви більшості астрономічних спостережень, починаючи від історичних рядів Ф.В.Бесселя ізакінчуючи широтними спостереженнями Міжнародної служби руху полюсів Землі [IGY-Data, 1959; IGC-Data , 1959; Post-IGC-Data, 1960; Yumi,1962]. Перший етап цих досліджень був закінчений в 1974 p. [Dzhun, 1974], який підтвердив суттєво більшу адекватність розподілу Пірсона-Джеффріса дійсній практиці спостережень при обсязі вибірок $n>500$. Другий етап досліджень висновків Джеффріса мав показати їх універсальність для різних галузей науки. Він розпочався разом з реалізацією космічних досліджень по Міжнародній програмі Monitoring Earth Rotation and Intercomparing the Techniques of observation and analysis (MERIT), в якій в два етапи з 01.08.1980 - 31.11.1980 і з 01.09.1983 - 31.10.1984 приймали участь 22 країни [AES, 2003]. Головна астрономічна обсерваторія АН України була учасником цього проекту. Разом з цим адекватність висновків Джеффріса перевірялась в астрометрії [Dzhun, 1974, 1988, 1992, 1992, 1992, 2011, 2012; Charin, 1970], космічних дослідженнях [Dzhun, 1991, 1992], геофізиці [Dzhun, Somov, 1995], гравіметрії [Dzhun, 1984], геодезії [Dzhun, 1989, 2010], економіці [Dzhun, 1989, 2002, 2003, Gazda, 1999, 1999]. В результаті аналізу більше ніж 130000 спостережень в різних галузях науки було показано, що розподіл Пірсона-Джеффріса VII типу має дійсно універсальний характер. Істотні середньозважені негаусові ексцеси $\varepsilon$ цього розподілу були наступними для спостережень: економічних $\varepsilon=2,895 \pm 0,142$; космічних $\varepsilon=1,719 \pm 0,052$; астрономічних $\varepsilon=1,077 \pm 0,015 ;$ гравіметричних $\varepsilon=0,810 \pm 0,105$; геодезичних $\varepsilon=0,767 \pm 0,034$; фізичних (швидкість світла) $\varepsilon=1,451 \pm 0,10$.

Зауважимо, що для закона Гауса $\varepsilon=0$.

Другий етап масової перевірки висновків Джеффріса закінчився в 1992 р. [Dzhun,1992], який і показав їх універсальність. Усі розроблені нові процедури аналізу даних були об'єднані в рамках «Некласичної теорії похибок вимірів» (НТПВ) [Dzhun, 2015]. 


\section{Фундаментальні постулати НТПВ}

КТП опирається на два фундаментальних постулати [Gauss, 1823]:

- похибки спостережень підкоряються закону Гауса;

- в результатах спостережень відсутні систематичні похибки.

На відміну від КТП, НТПВ грунтується на трьох фундаметальних постулатах:

1. При кількості багатократних спостережень $n>500$ ïx випадкові незалежні похибки підкоряються закону Пірсона-Джеффріса (1) 3 показником степені m, (який є мірою відхилення від закону Гауса) в межах $3 \leq m \leq 5$.

Для закону Гауса $m=\infty$. Як бачимо, значення $m$ для розподілів похибок великого обсягу, досить далеко відхиляється від значення $m=\infty$, властивого для нормального закону.

2. Індивідуальні ваги спостережень, які підкоряються закону ПірсонаДжеффріса, характеризує їх вагова функція:

$$
P\left(x_{i}\right)=\left[\left(\frac{m-0.5}{m}\right)^{3} \sigma+\frac{v_{i}^{2}}{2 m}\right]^{-1}, \quad v_{i}=x_{i}-a,
$$

де $\mathrm{a}, \sigma, \mathrm{m}$ - максимально-правдоподібні $\quad$ оцінки $\quad$ (ММП-оцінки) параметрів розподілу (1);

$\mathrm{P}\left(x_{i}\right)$ - обернена дисперсія (вага) спостереження $x_{i}$.

Впливом слабих, невиключених, корельованих систематичних похибок можна знехтувати лише в тому випадку, коли вагова функція похибок вимірів (2) є несингулярною.

Необхідно зазначити, що вагова функція $є$ несингулярною лише в тому разі, коли критеріально доказана відповідність дійсного розподілу похибок формі (1).

Сингулярною вагова функція (2) є в тому випадку, коли розподіл похибок має значиму асиметрію. Зазначимо, що ще Д. I. Менделеєв, великий російський хімік, блискучий експериментатор, вперше висловив думку, що нульова асиметрія похибок є об’єктивним доказом якісно проведеного експерименту [Malikov, 1979]. Проте в часи Д. I. Менделеєва, його думка не була підтверджена теорією. Вперше це 
зроблено в НТПВ. Але відсутність асиметрії є недостатньою умовою. Сингулярність спостерігається також при значимій плосковершинності дійсного розподілу похибок вимірів.

\section{Області застосування НТПВ}

НТПВ використовується при обробці даних і математичному моделюванні в тому разі, коли обсяги багатократних вибірок $n>500$. Дослідження показують [Dzhun, 2015], що при $n>50075-80 \%$ рядів похибок підкоряються закону Пірсона - Джеффріса. Як правило, великі обсяги властиві сучасним автоматизованим довгостроковим експериментам в економіці, в космічних дослідженнях, астрономії, квантовій фізиці, гравіметрії, геодезії, метрології, тощо.

\section{Висновки}

1. Адекватність гіпотези про форму розподілу похибок в сучасних експериментах має інтервальний характер на шкалі обсягів спостережень $n$. Так, при обсягах спостережень в межах $30<n<$ 500, як правило, робочий характер має гіпотеза про їх нормальний розподіл. При обсягах спостережень $500<n<5000$ [Dzhun, 2012], адекватним і набагато більш спроможним $є$ прийняття гіпотези про закон похибок Пірсона-Джеффріса.

2. Не існує якогось всезагального закону похибок для великих вибірок 3 певним значенням міри відхилення $m$ від закону Гауса. Навпаки, кожна система спостережень чи вимірів, певний інструмент має своє значення $m$, своє властиве йому відхилення від нормального закону, яке і $є$ основною метрологічною характеристикою вимірювального метода спостережень.

3. Дуже важливо знати, що застосування вагової функції в процедурах НТПВ дозволяє визначити ефективні оцінки шуканих параметрів, оскільки дія аномальних похибок буде подавлена. Ця болюча проблема КТП ефективно вирішується в рамках НТПВ.

В умовах автоматизації і комп'ютеризації вимірів, кожному досліднику - експерементатору, вченому в галузі «Data analysis», необхідно знати, що таке НТПВ і як застосовувати ії методи. 


\section{Bibliography}

AES (2003). Astronomichny encyklopedychny slovnyk [Astronomical encyklopaedy dictionary] Lviv. c. -548.

Dzhun I.V. (1974). Analiz parallelnyih shirotnyih nablyudeniy, vypolnennyh po obschey programme [Analysis of parallel latitudinal observations performed under the general program]: avtoref. dis... na soiskanie uch. steneni kand. fiz.-matem. nauk: spets. 01.03.01. Astrometriya i nebesnaya mehanika [Astrometry and Celestial Mechanics], Kyiv: Institut matematiki AN USSR, p. 19.

Dzhun I.V. (1984). Arnautov G.P., Stus Yu. F., Sheglov S.N. Osobennost zakona raspredeieniya rezultatov ballisticheskih izmereniy uskoreniya silyi tyazhesti [A feature of the distribution law of the results of ballistic measurements of acceleration due to the gravity]. Povtornie gravimetricheskie nablyudeniya [Repeated Gravimetric Observation]. Izd. MGK pri Prezidiume AN SSSR i NPO „Neftegeofizika”, Moscov: 1984, p. 87-100.

Dzhun I.V. (1989). Ob approksimacii plotnosti verojatnosti nekotorych rjadov oshibok geodezicheskih izmerenij raspredeleniem Pirsona VII tipa. [On approximating the Probability Density of Some Error Series in Geodetic Measurements by the Pearson Distribution of type VII] / Izvestija VUZ. Geodeziya i Aerofotosemka, No. 6, p. 43-48.

Dzhun I.V. (1991). Pearson's Distribution of Type VII of Errors of satellite Laser Ranging Data. // Kinematics and Physics of Celestial Bodies, - vol. 7, Allerton Press, Inc. New York, p. 74-84.

Dzhun I.V. (1992). About make use of Pearson's Distribution of Type VII of the Approximation of observation's Errors in Astrometry. Measurements Techni ques, vol. 35, No. 3. Springer.

Dzhun I.V., Slavinskaja A.A. (1988). Obrabotka nablyudenij na astroljabiy Danzhona s uchetom ekscesa zakona oshibok ostatochnych pogreshnostej [Treatment of Observations on the Danjon Astrolabe given Excess Residual Error of the law of Error]. /Izuchenie Zemli kak planety metodami geofiziki, geodezii i astronomii. Tr. // Orlovskoj konferencii (Poltava, 22 sentjabrya - 3 oktjabrya 1986 g.): Naukova dumka, 1988 g, p. 222-226.

Dzhun I.V. (1992). Matematicheskaja obrabotka astronomicheskoj i kosmicheskoj informacii pri negaussovych osibkach nabljudenij: avtoreferat dis. na soisk. uch. stepeni doctora fiz.-mat. nauk: spec. 01.03.01 „Astrometrija i nebesnaja mechanika” „Kiev, GAO NAN Ukraine, Kiev, s. 4 [Mathematical Treatment of Astronomical and Space-Based Information in non-Gaussian Observation Errors: Extended Abstract of Doctoral Dissertation in Physics and Mathematics, Gol. Astron. Observ. Akad. Nauk Ukrainy, Kiev, p. 46. 
Dzhun I.V. (1998). The Problem of Probability Methods in Economics. Economica Firiem, 1998. Bardejovske Kupele, 5.5-6-5, 1998, p. 444-448.

Dzhun I.V. „Novitskii P.V. (1992). Comments of Use of the Type VII Pearson Law in Astrometry. Kinematics and Physics of Celestial Bodies, vol. 8. No 5. p. 78-81. Allerton Press. Inc. - New York.

Dzhun I.V. Gazda V. (2002). About Distribution of Stock Index Returns Fluctuations. Business Review. Scientific Jornal of the Faculty of Business Economics of the Univercity of Economics in Bratislava with a seat in Kosice, vol. 1, p. 20-27.

Dzhun I.V., Somov V. I. (1995). O nekotorych fundamentalnych voprosach mathematicheskoj obrabotki geofizicheskoi informacii [About some Fundamental Question of the Mathematical Treatment of the Geophysical Informations]. Ceodinamicheskie ussledovanija v Ukraine. Sb. nauch. trudov Instituta geofiziki NAN Ukrainy [Ceodinamics Investigation in Ukraine. Coll. of scientific Works Geophysical Institute NAS Ukraine, Kiev, p. 167-178.

Dzhun J.V. (2010). Garold Dzheffric i jogo zakon pochibok. [Harod Jeffreys and its Errors Law]. Geodezija, kartografija i aerofotoznimannja, Ukraine, Lviv, No. 73, p. 133-137.

Dzhun J.V. (2011). Method for diagnostics of the mathematical models in theoretical astronomy and astrometry, „Kinematics and Physics of Celestial Bodies”. Allerton Press, Inc., vol. 27, No. 5, p. 260-264.

Dzhun J.V. (2012). Distribution of Errors in Multiple Large Volume Observations. Measurement Techniques. Vol. 55, No. 4, p. 393-396, Springer.

Dzhun J.V. (2012). What are differences „observation-calculation” bound to be during modern experiments in astrometry, „Kinematics and Physics of Celestial Bodies”, Allerton Press, Inc, vol. 28, No. 1, p. 70-78, .

Dzhun J.V. (2015). Neclasichskaya teoriya peogreshnostey izmereniy [Non-classical Error Theory in Measurement] Rivne, Estero Publ., p. 168.

Dzhun J.V., Gazda V. (2003). O neplatnosti predpolady normality rozdelenia vynosnosti kapitalovych aktiv. Economic Review. Quarterly Journal of the Univercity of Economics Bratislava, vol. XXXII, No. 3, p. 303-308.

Gauss C.F. (1823). Theoria combinationis observationum erroribus minimis obnoxiae.

Gazda V. (1999). Normal Probability Distribution in Financial Theory - False Assumption and Consequences. In: Proccedings of the conference „The Process of Education and Upbringing in Higher and Learning Schools - the Ways of Development and Improvement", Rivne: International University in Rivne, p. 73-75. 
Gazda V., Dzhun J.V. (1999). About the Distribution of random Oscilations of Stock Index RMS - 100. Economika Firiem, Kosice: 9 - 10.09.1999.

Geary R.C. (1936). Distribution of student's ratio for non-normal samples. Journal of the Royal Statistical Society, suppl. 3.

Hattory T. (1951). Latitude observations with floating zenith telescope at Mizusawa. PILOM, No 1.

IGC - Data (1959) on Longitude and Latitude, part. 1. Observed at the ILS of Mizusawa, Tokyo.

IGY - Data (1959) on Longitude and Latitude, part. 1. Observed at the ILS of Mizusawa, Tokyo.

Jeffreys H. (1937). The Law of Errors and the Combinations of Observations. Philos. Trans. Roy. Soc. London, ser. A., No. 237, p. 231-271.

Jeffreys H. (1939). The law of errors in the greenwich variation of latitude observations, „Mon. Not. Of the RAS”, vol. 99, No 9, p. 703-709.

Jeffreys H. (1940). Theory of probability, Oxford: Sec. Eddition, p. 468.

Kemnic Yu.V. (197). Matematicheskaja obrabotka resultatov geodezicheskich izmerenij, [Mathematical's Treatment of the Results of geodezical's Measurements]. Moscow: VINITI. Itogi nauki. Ser. Geodeziya i aerosemka, No. 7, p. 5-23.

Kemnic Yu.V., Vlasov V.D. (1978). Teorija i metodu matematicheskoj obrabotki rezultatov geodezicheskih izmerenij. [The Theory and Methods of Mathematical's Treatment of the Results of geodezical's Measurements]. Moscow: VINITI: Itogi nauki i techniki, ser. Geodeziya i aeros'emka, No. 14, p. 116

Khavin A.S. (1970). Yatskiv Ya. S. Izuchenie oshibok nablyudenij Goloseevckogo Kataloga zvezd shirotnych program. [Analysis of the observational error of the Goloseyevo catalogue of latitude stars. 1]. Astrometrija i astrofizika, No 10, p. 34-43.

Lukacs E.A. (1942). A characterization of the normal distribution, Annals of Mathematical Statistics, vol. 13, No. 91.

Malikov M.V. (1979). Osnovy metrologii [Principles of Metrology]. Komitet po Delam Mer i izmeritelnyh Priborov pri SM SSSR, Moscow.

Marcuze Yu.I. (1985). Matematichescaja obrabotka resultatov geodezicheskih izmerenij. [of Mathematical's Treatment of the Results of geodezical's Measurements], Moscow: VINITI: Itogi nauki i techniki, No. 23, p. 3-17.

Novickij P.V., Zograf P.V. (1991). Ocenka pogreshnostej rezultatov izmerenij [Estimation of Errors of the Results of the Measurements]. Energoatomizdat, Leningrad, p. 304 . 
Orlov A.I. (1991). Chasto li racpredelenie resultatov nablydenij javliaetsja normalnym? [Is the distribution often normal?]. Zavodskaja Laboratorya, No 7, p. 62-64.

Pearson K. (1902). On The mathematical theory of errors of judgment with special reference to the personal equation, „Philosophical Transactions of the Royal Society of London" Ser. A. vol. 198, p. 253-296.

Post - IGC - Data (1960) on Longitude and Latitude. Observed at the ILS of Mizusawa, Tokyo.

Volzhanin S.D. (1984). Metod Lp - ocenok i ego ispol'sovanie v geodezicheskih urovnitelnyh vychislenijah. [Lp - method Evoluations and its use in Geodetic Equalization Calculations]. Author's abstract. Lvov, p. 20.

Yumi S. (1962). PILOM, vol. IV, No. 1. 
